\title{
Funic Presentation
}

National Cancer Institute

\section{Source}

National Cancer Institute. Funic Presentation. NCI Thesaurus. Code C113494.

The positioning of the umbilical cord before the main presenting part of the fetus. 